\title{
Maternal bereavement shortly before or during pregnancy and risk of postpartum psychotic illness: a population-based study from Denmark and Sweden
}

This article was published in the following Dove Press journal:

Clinical Epidemiology

\begin{abstract}
Pauline Warselius'
Sven Cnattingius'

Jiong $\mathrm{Li}^{2}$

Dang $\mathrm{Wei}^{3}$

Unnur Anna Valdimarsdottir ${ }^{4,5}$

Kyriaki Kosidou, ${ }^{3,6}$

Johan Reutfors'

Jørn Olsen ${ }^{2,7}$

Mogens Vestergaard ${ }^{8,9}$

Carsten Obel ${ }^{8,9}$

Krisztina D László ${ }^{3}$

'Department of Medicine Solna, Karolinska University Hospital and Karolinska Institutet, Stockholm, Sweden;

${ }^{2}$ Department of Clinical Epidemiology, Aarhus University, Aarhus, Denmark;

${ }^{3}$ Department of Public Health Sciences, Karolinska Institutet, Stockholm, Sweden; ${ }^{4}$ Department of Medical Epidemiology and Biostatistics, Karolinska Institutet, Stockholm, Sweden; ${ }^{5}$ Faculty of Medicine, University of Iceland, Reykjavik, Iceland;

${ }^{6}$ Centre for Epidemiology and

Community Medicine, Stockholm

County's Health Care District,

Stockholm, Sweden; ${ }^{7}$ Department of Epidemiology, School of Public Health, University of California, Los Angeles, CA, USA; ${ }^{8}$ Department of Public Health, Aarhus University, Aarhus, Denmark; ${ }^{9}$ Research Unit and Section for General Practice, Department of Public Health, University of Aarhus, Aarhus, Denmark
\end{abstract}

Correspondence: Krisztina D László Department of Public Health Sciences, Karolinska Institutet, Tomtebodavägen I8A, level 3, Stockholm 17|77, Sweden Tel +4 673020 976I

Email krisztina.laszlo@ki.se
Purpose: Postpartum psychosis is a rare but severe complication following childbirth, with unknown etiology. This study investigated whether the death of a close family member - a source of severe stress - the year before or during pregnancy was associated with an increased risk of psychotic illness in the postpartum period among women without and with a history of psychiatric disorder.

Methods: We studied live births in Denmark during 1978-2008 and births in Sweden during 1973-2006 $(n=5,246,978)$. Information on death of women's relatives and partners and sociodemographic, health-, and pregnancy-related factors was obtained through linkage with nationwide registries.

Results: The death of a close relative the year before or during pregnancy was not associated with psychotic illness during the first 90 days postpartum among women without (adjusted HR $1.02,95 \%$ CI $0.76-1.37$ ) or with a history of psychiatric disorder (HR $0.96,95 \%$ CI 0.74-1.25). Similarly, there was no association between bereavement and risk of postpartum psychosis according to the timing of the loss (the year before or during pregnancy), the relative's cause of death (natural or unnatural), or the woman's relationship to the deceased (parent/sibling or partner/older child).

Conclusions: Death of a close relative, one of the most severe sources of stress, before or during pregnancy was not associated with postpartum psychosis. Therefore, these data do not support the hypothesis that severely stressful life events, such as bereavement around the time of pregnancy, are associated with postpartum psychosis.

Keywords: postpartum, psychosis, bereavement, stress, pregnancy, cohort study

\section{Introduction}

Postpartum psychosis is a severe psychiatric disorder that affects one to two in 1,000 childbearing women, ${ }^{1-3}$ often with severe consequences for the affected women and their families. ${ }^{4,5}$ The etiology is not clear, 4,5 but a suggested potential explanation is that psychological, circadian, hormonal, and immune-system changes associated with pregnancy and parturition may trigger psychotic symptoms in the postpartum period, in particular in vulnerable women. ${ }^{5-8}$

Stressful life events have been associated with an increased risk of a first psychotic episode and possibly with recurrent events in patients with a history of psychotic illness. ${ }^{9}$ Possible underlying mechanisms involve changes in affective and cognitive 
function, ${ }^{9}$ dysregulation of the hypothalamic-pituitary-adrenal axis, abnormalities in the dopaminergic system, reductions in hippocampal volume, and increased inflammatory activity. ${ }^{10}$ According to the neural diathesis-stress model of psychosis, the effect of stress on psychosis may be stronger in the presence of diatheses, ie, preexisting or situational factors that increase vulnerability to a psychotic episode. ${ }^{10,11}$ Women's susceptibility to psychosis is substantially higher in the postpartum period than in the years before or after childbirth. ${ }^{4}$, Similarly, a history of psychiatric disorders is a well-known risk factor for postpartum psychosis. ${ }^{5,8}$ Risks are highest among women with a history of bipolar disorder and schizophrenia, but increased postpartum-psychosis rates have been reported also for women with other psychiatric disorders, primarily unipolar affective disorders. ${ }^{6,8,12-14}$ Patients with psychotic and mood disorders have poorer coping skills, higher baseline cortisol levels and increased hypothalamic--pituitary-adrenal-axis reactivity to stress than women without a history of psychiatric disorders ${ }^{10}$ and consequently the effect of stressful events on psychosis in the highly stress-sensitive postpartum period may be stronger in the former groups.

To our knowledge, only three studies addressed the link between maternal stressors during pregnancy and the risk of a psychotic episode in the postpartum period. ${ }^{12,15,16}$ Brockington and associates assessed six months after delivery adverse life events in the past 38 weeks in 33 women with postpartum psychosis and 80 randomly selected women with a recent childbirth. ${ }^{15}$ Similarly, Dowlatshahi and Paykel conducted three months postpartum semistructured interviews about adverse life events in the past 13 months in 33 recently delivered severely ill psychiatric patients (most with psychosis), and in 33 puerperal controls with no mental disorder during pregnancy or postpartum. ${ }^{16}$ Marks and colleagues studied the association between negative life events one year prior to the postpartum period and the risk of postpartum psychotic relapse in 43 women with a history of severe depression or psychosis. ${ }^{12}$ None of the three studies reported an association, but since all three studies were small, involved only few patients with postpartum psychosis, ${ }^{12,15,16}$ and two of these studies were subject to recall bias, ${ }^{15,16}$ further studies are needed.

Death of a close relative is one of the most severe stressors. ${ }^{17,18}$ Death of a child and suicidal death of a spouse are rated 6 on a six-steps scale of severity of stress (ie as "catastrophic stressors"), while other deaths in the close family are rated 5 (ie as "extreme stressors"). ${ }^{17}$ Another well-known classification system of sources of stress considers the death of the spouse the life event that requires the greatest level of readjustment, followed closely by death of a close family member. ${ }^{18}$ The magnitude of the emotional stress experience may vary also according to the cause of death, with sudden, unnatural deaths being more likely to be perceived as more stressful than natural deaths.19 Thus, if emotional stress is part of the etiology behind postpartum psychosis, we would expect an increased risk of postpartum psychosis following bereavement before childbirth, in particular after the death of a nuclear family member or after sudden, unnatural deaths of relatives.

We investigated whether the death of a close family member, ie parent, sibling, partner or older child, the year before or during pregnancy was associated with an increased risk of a psychotic illness in the postpartum period among women without and with a history of psychiatric disorder.

\section{Material and methods}

\section{Study design and data sources}

This cohort study includes all live births during 1978-2008 as reported in the Danish Medical Birth Register (MBR) ${ }^{20}$ and all births during 1973-2006 included in the Swedish $\mathrm{MBR}^{21}(\mathrm{~N}=5499$ 333). Both MBRs contain on-time collected data on more than $98 \%$ of the deliveries in each country. $^{20,21}$ To obtain information on the death of the women's family members, sociodemographic and healthrelated factors, the cohort was linked to several populationbased registries. $^{22}$ The Danish MBR was linked to the Civil Registration System, ${ }^{23}$ the Psychiatric Central Register, ${ }^{24}$ the National Hospital Register ${ }^{25}$ and the Integrated Database for Longitudinal Labor Market Research. The Swedish MBR was linked to the Multi-generation Register, the Cause of Death Register, ${ }^{26}$ the Patient Register ${ }^{27}$ and the Education Register. $^{28}$ Causes of death and medical diagnoses were coded according to the Danish and Swedish versions of the International Classification of Diseases (ICD); all ICD-codes used to define medical conditions in our study are presented in Table $\mathrm{S} 1$.

A total of 2085521 deliveries were recorded in the Danish Medical Birth Register during the period 19782008 and 3413812 deliveries in the Swedish Medical Birth Register during the period 1973-2006 ( $\mathrm{N}=5499$ 333). We first excluded 231151 births with an unlikely short $(<22$ completed weeks), long $(>45$ weeks in Denmark and $>46$ weeks in Sweden) or missing gestational age and 99 further births by women with no personal identification number (Figure 1). We performed separate analyses 


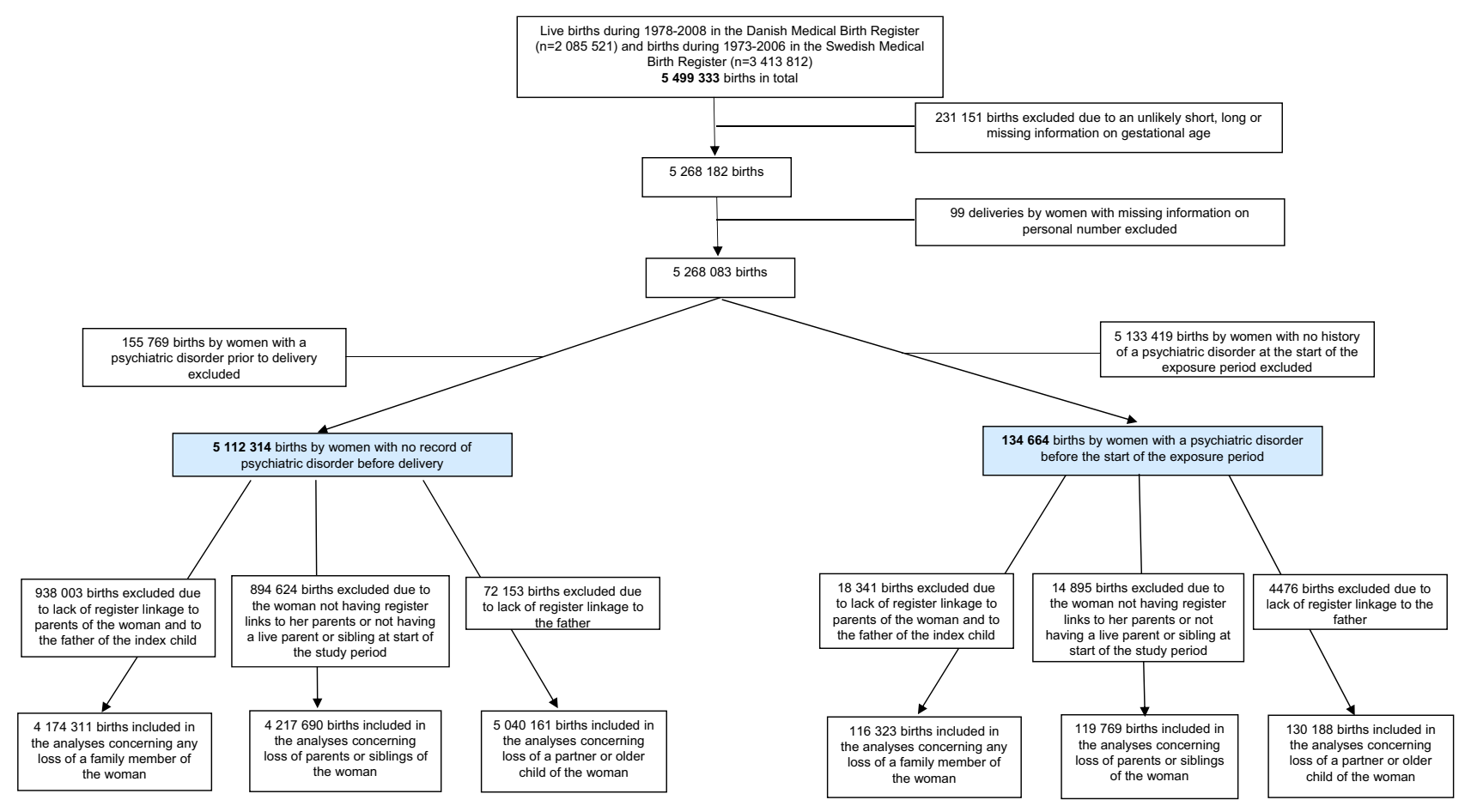

Figure I Flowchart of study participants.

among births by women with no record of psychiatric disorder before delivery ( $\mathrm{n}=5112314$ ) and among births by women who had a record of a psychiatric disorder before the start of the exposure period (one year before conception) $(n=134$ 664) in the Danish Psychiatric Central Register, the Danish National Hospital Register or the Swedish Patient Register (Figure 1). The Danish Psychiatric Central Register includes information on all hospitalizations for psychiatric disorders since 1969 and on all out-patient psychiatric care since 1995. ${ }^{24}$ The Danish National Hospital Register includes information on all in-patient care in Denmark since $1977^{25}$ and on all outpatient care since 1995. The Swedish Patient Register was established in 1964 and its coverage increased gradually until 1987, when it became nationwide; for the period 1973-1986 coverage of psychiatric hospitalizations is considered complete in all but five of the 25 Swedish counties. ${ }^{27}$

The study was approved by the Data Protection Agency in Copenhagen (no. 2008-41-2680), the Scientific Ethics Committee of Central Region Jylland (no. M-20100252) and by the Research Ethics Committee at Karolinska Institutet, Stockholm (no. 2008/4:6) in Sweden.

\section{Measures}

Exposure was defined as the death of a close family member of the pregnant woman the year before or during pregnancy, ie parent, sibling, older child or partner. The relatives were identified in the Danish Civil Registration System or in the Swedish Multigeneration Register. In the Swedish Multigeneration Register, linkage to partners was only possible for livebirths. Information on date and cause of the relatives' death was obtained from the Danish Civil Registration System and from the Swedish Cause of Death Register. Exposure was classified according to 1) the time of death (the year before pregnancy or during pregnancy), 2) the relative's cause of death (natural or unnatural death) and 3) the woman's relationship to the deceased (parent or sibling and partner or child). If the woman lost several relatives during the study period, only the timing of the first loss was considered in the analyses.

The primary outcome was a diagnosis of psychotic illness at any time in the first 90 days after delivery ${ }^{1,4,7,13,29}$ in the Danish Psychiatric Central Register, the Danish National Hospital Register or the Swedish Patient Register. A diagnosis of postpartum psychosis is usually given by psychiatrists based on the criteria of the Diagnostic and Statistical Manual of Mental Disorders. Since there is not full consensus on which diagnoses should be included in the definition of postpartum psychosis, ${ }^{4,30,31}$ we defined the combination of psychotic illness and depression in the first 90 days after delivery as a secondary outcome (see Table S1 for ICD codes). 
Potential covariates: Data on the women's highest attained education was obtained from the Danish Integrated Database for Longitudinal Labour Market Research $^{32}$ and from the Swedish Education Register, ${ }^{28}$ whereas information on their country of origin was from the Danish Integrated Database for Longitudinal Labour Market Research and from the Swedish MBR. Information on date of delivery, the woman's age at childbirth, smoking (available since 1982 in Sweden and since 1991 in Denmark), height and weight in early pregnancy (available only in Sweden, since 1992) was obtained from the MBRs; body-mass index was calculated by dividing weight in kilograms with the square of the height in meters. Data on maternal and family hospitalizations for psychiatric disorders prior to the year before pregnancy was obtained from the Danish Psychiatric Central Register, the Danish National Hospital Register or the Swedish Patient Register.

\section{Statistical analyses}

Cox regression models were used to estimate risk ratios of postpartum psychosis for exposed in comparison with unexposed according to 1) the time of the loss, 2) the relative's cause of death, and 3) the woman's relationship to the deceased (a parent or sibling versus an older child or partner) and the risk of postpartum psychotic illness in the 90 days after delivery. Since women could have had several births during the study period and the observations are thus not completely independent from each other, we applied the Covsandwich procedure in SAS to take into account the similarity between births by the same woman. Women were followed from delivery until their first psychotic event, death, emigration, or the end of follow-up defined as 90 days postpartum, whichever came first; right censoring was applied. The assumption of proportional hazards was examined using the interaction between exposure and time and the $\ln$ of time. Analyses were performed separately 1) among births by women with no record of psychiatric disorder before delivery, and 2) among births by women with a history of psychiatric disorder at the start of the exposure period (Figure 1). Analyses concerning death of any family member of the woman during the exposure period were restricted to births by women with register linkage to parents and to the father of the index child (Figure 1). Analyses concerning loss of parent or sibling of the woman were restricted to births by women with register linkage to parents and at least one live parent or one live sibling at the start of the exposure period (Figure 1 and Table 1). Analyses regarding the association between the death of the partner or an older child of the woman were conducted among births by women with registered linkage to the father of the index child (Figure 1). Adjustments were made for country (Denmark or Sweden), year of delivery, ${ }^{4}$ the woman's age, ${ }^{4}$ country of origin, ${ }^{4}$ education, ${ }^{4}$ the birth order of the index delivery 5,8 and family history of a psychiatric disorder (parents, sibling and/or partner of the woman). ${ }^{5,8}$ The potential confounders were chosen based on their association with the exposure and their established or plausible association with the outcome. In sensitivity analyses, we also adjusted for two measures that could be both confounders and mediators of the investigated association, ie 1) smoking in analyses restricted to deliveries in 1991 or later in Denmark and in 1982 or later in Sweden, and 2) obesity among deliveries in 1992 or later in Sweden. We investigated potential effect measure modification by country, year of delivery, the woman's age, country of origin and family history of psychiatric disorder, using stratified analyses and formal tests of interaction. We also repeated our analyses concerning any loss during the exposure period, and with exposure categorized according to the time and cause of the relative's death and the woman's relationship to the deceased, and postpartum psychosis risk among births by women with a history of (1) psychotic or bipolar disorder and (2) depression/anxiety at the start of the exposure period; the ICD codes used to define these medical conditions are presented in Table S1. Finally, we performed analyses with the secondary outcome, ie the combination of psychotic illness and depression in the first 90 days after delivery. For this outcome, we analyzed any loss during the exposure period, exposure categorized according to the time and the cause of the relative's death, and the woman's relationship to the deceased.

Analyses were performed using SAS 9.4 (SAS Institute Inc, Cary, North Carolina).

\section{Results}

In the cohort of 4174311 childbirths of women with no record of psychiatric disorder before delivery 126264 were exposed to bereavement; among the 116323 deliveries by women with a history of psychiatric disorder at the start of the exposure period 4129 were exposed. In both of the above cohorts, exposed women were more likely to be older, give birth in earlier calendar years of the study period, be multiparous, have less education, smoke in early pregnancy and have a family history of psychiatric disorders before conception (Table 1). The association between the study variables and the risk of postpartum psychosis is shown in Table S2. 
Table I Characteristics of study participants by women's history of psychiatric disorder.

\begin{tabular}{|c|c|c|c|c|}
\hline \multirow[t]{3}{*}{ Study variables } & \multicolumn{2}{|c|}{$\begin{array}{l}\text { Births by women with no record of psy- } \\
\text { chiatric disorder before delivery ( } N=4 \\
\text { I74 } 3 \text { III })^{a}\end{array}$} & \multicolumn{2}{|c|}{$\begin{array}{l}\text { Births by women with a record of psy- } \\
\text { chiatric disorder prior to one year } \\
\text { before conception }(n=116323)^{a}\end{array}$} \\
\hline & \multicolumn{2}{|c|}{$\begin{array}{l}\text { Loss of a close family member the year } \\
\text { before or during pregnancy } N(\%)\end{array}$} & \multicolumn{2}{|c|}{$\begin{array}{l}\text { Loss of a close family member the year } \\
\text { before or during pregnancy } N(\%)\end{array}$} \\
\hline & $\begin{array}{l}\text { No } \\
(n=4048047)\end{array}$ & $\begin{array}{l}\text { Yes } \\
(n=126264)\end{array}$ & $\begin{array}{l}\text { No } \\
(n=|| 2 \text { |94) }\end{array}$ & $\begin{array}{l}\text { Yes } \\
(n=4 \mid 29)\end{array}$ \\
\hline \multicolumn{5}{|l|}{ Country } \\
\hline Sweden & $2746 \quad 177(67.8)$ & 83781 (66.4) & $68373(60.9)$ & $2535(6 I .4)$ \\
\hline Denmark & | $30 \mid 870$ (32.2) & 42483 (33.7) & 43821 (39.1) & $1594(38.6)$ \\
\hline \multicolumn{5}{|c|}{ Woman's country of origin } \\
\hline Denmark/Sweden & $3923664(96.9)$ & $123080(97.5)$ & $107969(96.2)$ & $4019(97.3)$ \\
\hline Other country & $122387(3.0)$ & $3133(2.5)$ & $4202(3.8)$ & $108(2.6)$ \\
\hline Missing & $1996(0.01)$ & $51(0.0)$ & $23(0.0)$ & $2(0.1)$ \\
\hline \multicolumn{5}{|c|}{ Woman's age at delivery (in years) } \\
\hline 19 or less & $124619(3.1)$ & 2367 (I.9) & $448 I(4.0)$ & $93(2.3)$ \\
\hline $20-24$ & $859100(21.2)$ & $18992(15.0)$ & $24378(21.7)$ & $649(15.7)$ \\
\hline $25-29$ & | $53 \mid 326(37.8)$ & $41685(33.0)$ & $36773(32.8)$ & $1194(28.9)$ \\
\hline $30-34$ & I $104030(27.3)$ & $40085(31.8)$ & $29757(26.5)$ & $1216(29.5)$ \\
\hline 35 or more & $428972(10.6)$ & $23135(18.3)$ & $16805(15.0)$ & $977(23.7)$ \\
\hline \multicolumn{5}{|l|}{ Year of delivery } \\
\hline $1973-1982$ & $861894(21.3)$ & $31080(24.6)$ & $9490(8.5)$ & 409 (9.9) \\
\hline $1983-1992$ & | 292763 (31.9) & 42758 (33.9) & $29280(26.1)$ & $1246(30.2)$ \\
\hline $1993-2002$ & | $28|6| 4(31.7)$ & $37423(29.6)$ & 40954 (36.5) & 1535 (37.2) \\
\hline $2003-2008$ & $611776(15.1)$ & $15003(11.9)$ & $32470(28.9)$ & $939(22.7)$ \\
\hline \multicolumn{5}{|l|}{ Parity } \\
\hline Primiparous & I 819044 (44.9) & 42830 (33.9) & 47031 (4I.9) & $1280(31.0)$ \\
\hline Multiparous & $2229002(55.1)$ & $83434(66.1)$ & $65163(58.1)$ & $2849(69.0)$ \\
\hline \multicolumn{5}{|l|}{ Woman's education } \\
\hline Basic school & $642556(15.9)$ & 24458 (19.4) & $32215(28.7)$ & I397 (33.8) \\
\hline Secondary school & I $842076(45.5)$ & 55468 (43.9) & $48007(42.8)$ & $1699(41.2)$ \\
\hline College/university & I 506216 (37.2) & $44840(35.5)$ & $30515(27.2)$ & 977 (23.7) \\
\hline Missing & $57199(1.4)$ & $1498(1.2)$ & $1457(1.3)$ & $56(1.4)$ \\
\hline \multicolumn{5}{|c|}{ Smoking in early pregnancy ${ }^{\mathrm{b}}$} \\
\hline No & $2172988(53.7)$ & $60092(47.6)$ & $54248(48.4)$ & $17 \mid 7(4 \mid .6)$ \\
\hline Yes & $543834(13.4)$ & $19585(|5.5|)$ & $3428 I(30.6)$ & 1472 (35.7) \\
\hline Missing & | $33 \mid 225$ (32.9) & $46587(36.9)$ & $23665(21.1)$ & $940(22.8)$ \\
\hline \multicolumn{5}{|l|}{ Obesity $^{c}$} \\
\hline No & $906318(22.4)$ & $22098(I 7.5)$ & $30 \quad 179(26.9)$ & $970(23.5)$ \\
\hline Yes & $89494(2.2)$ & $2786(2.2)$ & $3942(3.5)$ & $|5|(3.7)$ \\
\hline Missing & $3052235(75.4)$ & $101380(80.3)$ & $78073(69.6)$ & $3008(72.9)$ \\
\hline
\end{tabular}


Table I (Continued).

\begin{tabular}{|c|c|c|c|c|}
\hline \multirow[t]{3}{*}{ Study variables } & \multicolumn{2}{|c|}{$\begin{array}{l}\text { Births by women with no record of psy- } \\
\text { chiatric disorder before delivery }(N=4 \\
\text { I74 } 3 \text { II })^{\mathrm{a}}\end{array}$} & \multicolumn{2}{|c|}{$\begin{array}{l}\text { Births by women with a record of psy- } \\
\text { chiatric disorder prior to one year } \\
\text { before conception }(n=116323)^{a}\end{array}$} \\
\hline & \multicolumn{2}{|c|}{$\begin{array}{l}\text { Loss of a close family member the year } \\
\text { before or during pregnancy } N(\%)\end{array}$} & \multicolumn{2}{|c|}{$\begin{array}{l}\text { Loss of a close family member the year } \\
\text { before or during pregnancy } N(\%)\end{array}$} \\
\hline & $\begin{array}{l}\text { No } \\
(n=4048047)\end{array}$ & $\begin{array}{l}\text { Yes } \\
(n=126264)\end{array}$ & $\begin{array}{l}\text { No } \\
(n=|| 2 \text { | } 94)\end{array}$ & $\begin{array}{l}\text { Yes } \\
(n=4 \mid 29)\end{array}$ \\
\hline \multicolumn{5}{|c|}{ Partner's psychiatric disorder up to one year before conception } \\
\hline No & $3954313(97.7)$ & $123046(97.5)$ & $101658(90.6)$ & $3630(87.9)$ \\
\hline Yes & $93734(2.3)$ & $3218(2.6)$ & $10536(9.4)$ & $499(12.1)$ \\
\hline \multicolumn{5}{|c|}{ Psychiatric disorder in parents or siblings of the woman up to one year before conception } \\
\hline No & $3535597(87.3)$ & $100542(79.6)$ & $77401(69.0)$ & $2315(56.1)$ \\
\hline Yes & $512450(12.7)$ & $25722(20.4)$ & $34793(31.0)$ & $1814(43.9)$ \\
\hline
\end{tabular}

Notes: ${ }^{a}$ Analyses are conducted among births by women with register linkage to parents and to the father of the index child. ${ }^{b}$ Data were collected since 1982 in Sweden and since 1991 in Denmark. 'Data were available to us only in Sweden, since 1992.

\section{Main analyses}

In the cohort of births by women without a history of psychiatric disorder before delivery, we identified 1488 cases of psychotic illness during the first 90 days postpartum (0.4 per 1000 births). The loss of any relative the year before or during pregnancy was not associated with postpartum psychosis; the corresponding adjusted hazard ratio and $95 \%$ confidence intervals was $1.02(0.76-1.37)$ (Table 2). There was no marked association between bereavement and the risk of postpartum psychosis when exposure was categorized according to the time of the loss (the year before or

Table 2 Hazard ratios for a psychotic episode in the 90 days postpartum according to death of a close relative the year before or during pregnancy among women with no record of a psychiatric disorder before delivery.

\begin{tabular}{|c|c|c|c|c|}
\hline \multirow[t]{2}{*}{ Exposure } & \multirow[t]{2}{*}{$\mathbf{N}$} & \multirow[t]{2}{*}{ Events } & \multicolumn{2}{|l|}{ HR (95\% Cl) } \\
\hline & & & Unadjusted & Adjusted $^{\mathrm{a}}$ \\
\hline \multicolumn{5}{|c|}{ Any loss of a close relative the year before or during pregnancy ${ }^{a}$} \\
\hline Unexposed & 4048047 & 1440 & 1.00 & 1.00 \\
\hline Any loss & 126264 & 48 & $1.07(0.80-1.43)$ & $1.02(0.76-1.37)$ \\
\hline \multicolumn{5}{|l|}{ Time of the relative's death ${ }^{\mathrm{a}}$} \\
\hline The year before pregnancy & 75742 & 31 & $1.15(0.81-1.64)$ & $1.12(0.78-1.62)$ \\
\hline During pregnancy & 50522 & 17 & $0.95(0.59-1.53)$ & $0.86(0.53-I .4 I)$ \\
\hline \multicolumn{5}{|l|}{ Cause of the relative's death ${ }^{\mathrm{a}}$} \\
\hline Death due to natural cause & 111856 & 42 & $1.06(0.78-1.43)$ & $1.03(0.75-I .4 I)$ \\
\hline Death due to unnatural cause & 13936 & 6 & $1.21(0.54-2.70)$ & $0.92(0.38-2.22)$ \\
\hline \multicolumn{5}{|l|}{ Type of lost relative } \\
\hline Death of a parent or sibling ${ }^{b}$ & 113189 & 45 & I.II (0.82-I.49) & $1.01(0.75-1.38)$ \\
\hline Death of the partner or older child ${ }^{c}$ & $1850 \mid$ & 5 & $0.72(0.30-1.74)$ & $0.82(0.31-2.19)$ \\
\hline
\end{tabular}

Notes: ${ }^{a}$ Analyses were restricted to births by women with register links to parents and the father of the index child $(n=4$ I $743 \mathrm{I} I)$. Adjustment was made for country, year of delivery, the woman's age at the child's birth, country of origin, highest attained education, parity and psychiatric disorder in her parents, siblings and partner before the exposure period. ${ }^{b}$ Analyses were restricted to births by women who had register links to parents and at least a live parent or sibling at the start of the exposure period ( $\mathrm{n}=4217690$ ). Adjustment was made for country, year of delivery, the woman's age at the child's birth, country of origin, highest attained education, parity and psychiatric disorder before the exposure period in her parents and siblings. 'Analyses were restricted to births by women with register links to the father of the index child ( $\mathrm{n}=5$ 040 161). Adjustment was made for country, year of delivery, the woman's age at the child's birth, country of origin, highest attained education, parity and her partner's psychiatric disorder before the exposure period.

Abbreviations: $\mathrm{N}$, number; $\mathrm{HR}$, hazard ratio; $\mathrm{Cl}$, confidence interval. 
Table 3 Hazard ratios for a psychotic episode in the 90 days postpartum according to death of a close relative the year before or during pregnancy among women with a record of psychiatric disorder before the start of the exposure period

\begin{tabular}{|c|c|c|c|c|}
\hline \multirow[t]{2}{*}{ Exposure } & \multirow[t]{2}{*}{$\mathbf{N}$} & \multirow[t]{2}{*}{ Events } & \multicolumn{2}{|l|}{ HR (95\% Cl) } \\
\hline & & & Unadjusted & Adjusted $^{\mathrm{a}}$ \\
\hline \multicolumn{5}{|c|}{ Any loss of a close relative the year before or during pregnancy ${ }^{\mathrm{a}}$} \\
\hline Unexposed & 112194 & 1510 & 1.00 & 1.00 \\
\hline Any loss & 4129 & 61 & $1.10(0.84-1.43)$ & $0.96(0.74-1.25)$ \\
\hline \multicolumn{5}{|l|}{ Time of the relative's death ${ }^{\mathrm{a}}$} \\
\hline The year before pregnancy & 2416 & 34 & $1.05(0.75-1.47)$ & $0.92(0.65-1.29)$ \\
\hline During pregnancy & 1713 & 27 & $1.17(0.79-1.73)$ & $1.02(0.69-1.51)$ \\
\hline \multicolumn{5}{|l|}{ Cause of the relative's death ${ }^{a}$} \\
\hline Death due to natural cause & 3477 & 52 & I.II (0.83-I.49) & $0.95(0.7 I-I .27)$ \\
\hline Death due to an unnatural cause & 630 & 9 & $1.06(0.55-2.04)$ & $1.04(0.54-2.00)$ \\
\hline \multicolumn{5}{|l|}{ Type of lost relative } \\
\hline Death of a parent or sibling ${ }^{b}$ & 3810 & 55 & $1.02(0.77-1.34)$ & $0.88(0.67-1.16)$ \\
\hline Death of the partner or older child ${ }^{c}$ & 516 & 10 & $1.36(0.73-2.53)$ & $1.45(0.78-2.72)$ \\
\hline
\end{tabular}

Notes: analyses were restricted to births by women who had register links to parents and to the father of the index child ( $\mathrm{n}=\mathrm{I} \mid \mathrm{6} 323$ ). Adjustment was made for country, year of delivery, the woman's age at the child's birth, country of origin, highest attained education, parity and psychiatric disorder in her parents, siblings and partner before the exposure period. ${ }^{b}$ Analyses were restricted to births by women who had register links to parents and at least a live parent or a live sibling at the start of the exposure period ( $n=119$ 769). Adjustment was made for country, year of delivery, the woman's age at the child's birth, country of origin, highest attained education, parity and psychiatric disorder before the exposure period in her parents and siblings. 'Analyses were restricted to births by women with register links to the father of the index child $(n=130$ I88). Adjustment was made for country, year of delivery, the woman's age at the child's birth, country of origin, highest attained education, parity and her partner's psychiatric disorder before the exposure period.

Abbreviations: $\mathrm{N}$, number; $\mathrm{HR}$, hazard ratio; $\mathrm{Cl}$, confidence interval.

during pregnancy), the relative's cause of death (natural or unnatural) and the women's relationship to the deceased (parent/sibling or partner/older child).

In the cohort of births by women with a history of psychiatric disorder prior to the year before pregnancy, we identified 1571 cases of postpartum psychotic illness in the 90 days after delivery (13.5 per 1000 births). Like before, the loss of any relative was not associated with postpartum psychosis risk; the corresponding hazard ratio and $95 \%$ confidence interval was $0.96(0.74-1.25)$ (Table 3). We found no relation between bereavement and postpartum psychosis risk neither when exposure was categorized according to the time of the loss (the year before or during pregnancy), the relative's cause of death (natural or unnatural) and the women's relationship to the deceased (parent/sibling or partner/older child).

\section{Sensitivity analyses and analyses with the secondary outcome}

The association between bereavement the year before or during pregnancy and postpartum psychosis was not changed after additional adjustment for smoking (available since 1982 in Sweden and since 1991 in Denmark) ( $\mathrm{n}=2$ 796499 ) or obesity (available since 1992 in Sweden) ( $n=1$ 020 696). The association between bereavement the year before or during pregnancy and the risk of postpartum psychotic illness did not differ substantially across strata of country, year of delivery, the woman's country of origin, age and family history of any psychiatric disorder, neither among births by women without, nor among births by women with a history of psychiatric disorders. We found no association between 1) loss of a relative the year before or during pregnancy and, 2) loss of a relative categorized by time of death, 3) cause of death, and 4) the type of deceased relative and the risk of postpartum psychotic illness in analyses restricted to women with a record of psychotic or bipolar disorder (Table S3) or depression or anxiety (Table S4) at the start of the exposure period. Similarly, there was no association between death of any relative the year before or during pregnancy or when the loss was categorized by time of death, cause of death or type of deceased relative and the risk of the combined outcome of psychotic illness and depression in the 90 days postpartum (Table S5). 


\section{Discussion}

In this follow-up study based on nationwide data collected over more than three decades, we found no sign of causal association between the death of a close relative the year before or during pregnancy and the risk of postpartum psychosis, neither among women without, nor among women with a history of psychiatric illness.

The results are in line with those of three previous investigations, two case-control ${ }^{15,16}$ and one follow-up study, ${ }^{12}$ analyzing the link between maternal stress during pregnancy and the risk of postpartum psychosis and those of a follow-up study investigating the link between adverse life events in childhood and the risk of postpartum psychosis. ${ }^{33}$ These findings could be attributed to a lack of statistical power. We made a strong methodological contribution to the existing literature by 1) employing a follow-up design with independent measures of exposure and outcome, 2) a larger sample size involving virtually all births in two countries over three decades, 3 ) investigating potential dose-response effects (by cause of the relative's death and kinship to the lost person), and 4) performing analyses stratified by the woman's history of psychiatric disorder.

Though the etiology of postpartum psychosis is not known, the most commonly suggested potential causal explanation is that the psychological, circadian, hormonal and immune changes associated with pregnancy and delivery trigger psychotic symptoms in the postpartum period, in particular in women with a psychiatric history. ${ }^{5-8} \mathrm{We}$ hypothesized based on the neural diathesis-stress model of psychosis that maternal stress shortly before or during pregnancy could exacerbate the activity of the highly sensitized stress system characteristic to the postpartum period and increase the vulnerability to a psychotic episode. ${ }^{10,34}$ Our finding that death of a close relative, an event that is likely to cause severe stress for most affected individuals, ${ }^{18}$ was not associated with postpartum psychosis is in contrast with earlier results that adverse life events (as assessed by life event inventories or semi-structured interviews) may increase the risk of psychotic episodes ${ }^{9}$ in general population samples and of postpartum depression in childbearing women. ${ }^{35} \mathrm{~A}$ lack of an association could have several possible explanations. First, though our exposure was a severe acute life event likely to cause considerable emotional stress in most individuals, it is possible that a more chronic exposure than what we studied is necessary to provoke first-onset psychosis. ${ }^{10}$ Second, the mental health of bereaved patients with a history of psychiatric disorder is likely to have been closely followed during antenatal and postpartum care. Thus, women at high risk of a psychotic episode may have received prophylactic antipsychotic medication that attenuated the potential effect of stress on the risk of postpartum psychosis. ${ }^{8,10}$ Finally, it is possible that other hormonal and immune factors than those involved in the stress response ${ }^{7,8}$ or that the rapid changes in hormone levels and not their absolute levels are important for the development of postpartum psychosis. $^{34}$

Our study has limitations. First, postpartum psychosis is considered a psychiatric emergency that usually requires hospitalization, ${ }^{5,31}$ but some of the less affected women may not be treated in in-patient care and were consequently not recorded in the Danish National Hospital Register and the Central Psychiatric Register before 1995 or in the Swedish Patient Register. In addition, as the coverage of the Swedish Patient Register was not complete in five of the 25 Swedish counties prior to 1987 , and it is possible that some postpartum psychoses in this early time period were not recorded due to the incomplete reporting to the Patient Register. ${ }^{36}$ However, we found no differences in the investigated association by calendar period. Similarly, our secondary outcome involving the combination of postpartum psychosis and depression is likely to have captured only the most severe cases of depression, which may explain the lack of association between bereavement and the combined outcome of postpartum psychosis and depression. Second, although our sample size is large, due to the rarity of the exposure and the outcome the power to detect modest associations may have been limited in some of our sub-analyses as indicated by the wide confidence intervals. Third, albeit the exclusion of women who did not have register links to parents and siblings minimizes the possibility of misclassification of exposure, it may influence generalizability of our findings. Women whose relatives lived in Denmark or Sweden are likely to have better social support, better resources to cope with bereavement, and eventually a lower subsequent postpartum risk of mental disorders than the first generation immigrants.

\section{Conclusion}

We found no association between bereavement one year before or during pregnancy and the risk of postpartum psychosis, neither among women with, nor among women without a history of psychiatric disorder. Our findings do not support the hypothesis that stressful life 
events such as the death of a close family member may increase the risk of postpartum psychosis.

\section{Acknowledgments}

This work was supported by the Swedish Society of Medicine (grant SLS588081 to KDL), Karolinska Institutet Research Foundation (grant 2016 fobi50733 to KDL), Swedish Council for Working Life and Social Research (grant 2015-00837 to KDL), Danish Council for Independent Research (grant DFF-6110-00019 to JL), Karen Elise Jensens Fond (grant 2016 to JL), Nordic Cancer Union (grants 176673, 186200, and R217-A13234-18-S65 to JL), Novo Nordisk Fonden (grant NNF18OC0052029 to JL), TrygFonden (grants 904414 and 15199 to $\mathrm{CO}$ ), and the Lundbeck Foundation (grant R155-2012-11280 to MV). The funders were not involved in the design of the study, analyses, interpretation of the results, writing of the manuscript, or decision to submit the manuscript for publication.

\section{Disclosure}

The authors report no conflicts of interest in this work.

\section{References}

1. Terp IM, Mortensen PB. Post-partum psychoses. Clinical diagnoses and relative risk of admission after parturition. $\mathrm{Br} J$ Psychiatry. 1998;172:521-526. doi:10.1192/bjp.172.6.521

2. Kendell RE, Chalmers JC, Platz C. Epidemiology of puerperal psychoses. Br J Psychiatry. 1987;150:662-673.

3. VanderKruik R, Barreix M, Chou D, Allen T, Say L, Cohen LS. The global prevalence of postpartum psychosis: a systematic review. $B M C$ Psychiatry. 2017;17(1):272. doi:10.1186/s12888-017-1489-6

4. Valdimarsdottir U, Hultman CM, Harlow B, Cnattingius S, Sparen P. Psychotic illness in first-time mothers with no previous psychiatric hospitalizations: a population-based study. PLoS Med. 2009;6(2):e13. doi:10.1371/journal.pmed.1000013

5. Jones I, Chandra PS, Dazzan P, Howard LM. Bipolar disorder, affective psychosis, and schizophrenia in pregnancy and the post-partum period. Lancet. 2014;384(9956):1789-1799. doi:10.1016/S0140-6736 (14)61278-2

6. Munk-Olsen T, Laursen TM, Mendelson T, Pedersen CB, Mors O, Mortensen PB. Risks and predictors of readmission for a mental disorder during the postpartum period. Arch Gen Psychiatry. 2009;66 (2):189-195. doi:10.1001/archgenpsychiatry.2008.528

7. Hellerstedt WL, Phelan SM, Cnattingius S, Hultman CM, Harlow BL. Are prenatal, obstetric, and infant complications associated with postpartum psychosis among women with pre-conception psychiatric hospitalisations? BJOG. 2013;120(4):446-455. doi:10.1111/14710528.12073

8. Meltzer-Brody S, Howard LM, Bergink V, et al. Postpartum psychiatric disorders. Nat Rev Dis Primers. 2018;4:18022. doi:10.1038/ nrdp. 2018.22
9. Beards S, Gayer-Anderson C, Borges S, Dewey ME, Fisher HL, Morgan C. Life events and psychosis: a review and meta-analysis. Schizophr Bull. 2013;39(4):740-747. doi:10.1093/schbul/sbt065

10. Pruessner M, Cullen AE, Aas M, Walker EF. The neural diathesisstress model of schizophrenia revisited: an update on recent findings considering illness stage and neurobiological and methodological complexities. Neurosci Biobehav Rev. 2017;73:191-218. doi:10.1016/j.neubiorev.2016.12.013

11. Walker EF, Diforio D. Schizophrenia: a neural diathesis-stress model. Psychol Rev. 1997;104(4):667-685. doi:10.1037/0033295X.104.4.667

12. Marks MN, Wieck A, Checkley SA, Kumar R. Life stress and postpartum psychosis: a preliminary report. Br J Psychiatry Suppl. 1991; (10):45-49.

13. Harlow BL, Vitonis AF, Sparen P, Cnattingius S, Joffe H, Hultman $\mathrm{CM}$. Incidence of hospitalization for postpartum psychotic and bipolar episodes in women with and without prior prepregnancy or prenatal psychiatric hospitalizations. Arch Gen Psychiatry. 2007;64 (1):42-48. doi:10.1001/archpsyc.64.1.42

14. Wesseloo R, Kamperman AM, Munk-Olsen T, Pop VJ, Kushner SA, Bergink V. Risk of postpartum relapse in bipolar disorder and postpartum psychosis: a systematic review and meta-analysis. Am J Psychiatry. 2016;173(2):117-127. doi:10.1176/appi.ajp.2015.15010124

15. Brockington IF, Martin C, Brown GW, Goldberg D, Margison F. Stress and puerperal psychosis. Br J Psychiatry. 1990;157:331-334. doi:10.1192/bjp.157.3.331

16. Dowlatshahi D, Paykel ES. Life events and social stress in puerperal psychoses: absence of effect. Psychol Med. 1990;20(3):655-662. doi: $10.1017 /$ S0033291700017177

17. American Psychiatric Association A. Diagnostic and Statistical Manual of Mental Disorders: DSM-III-R. Washington, DC: APA; 1987.

18. Hobson CJ, Kamen J, Szostek J, Nethercut CM, Tiedmann JW, Wojnarowicz S. Stressful life events: a revision and update of the social readjustment rating scale. Int J Stress Manag. 1998;5(1):1-23. doi:10.1023/A:1022978019315

19. Parkes CM. Bereavement in adult life. BMJ (Clinical Research Ed). 1998;316(7134):856-859.

20. Knudsen LB, Olsen J. The Danish medical birth registry. Dan Med Bull. 1998;45(3):320-323.

21. National Board of Health and Welfare. The Swedish Medical Birth Register - A summary of content and quality. Available from: http:// wwwsocialstyrelsense/Lists/Artikelkatalog/Attachments/10655/2003112-3 20031123pdf. Accessed April 3, 2019.

22. Li J, Vestergaard M, Obel C, Cnattingus S, Gissler M, Olsen J. Cohort profile: the Nordic Perinatal Bereavement Cohort. Int $J$ Epidemiol. 2011;40(5):1161-1167. doi:10.1093/ije/dyq127

23. Pedersen CB, Gotzsche H, Moller JO, Mortensen PB. The Danish civil registration system. a cohort of eight million persons. Dan Med Bull. 2006;53(4):441-449.

24. Munk-Jorgensen P, Mortensen PB. The Danish psychiatric central register. Dan Med Bull. 1997;44(1):82-84.

25. Andersen TF, Madsen M, Jorgensen J, Mellemkjoer L, Olsen JH. The Danish National Hospital Register. A valuable source of data for modern health sciences. Dan Med Bull. 1999;46(3):263-268.

26. National Board of Health and Welfare. Dödsorsaker 2010. Causes of Death 2010. Availabale from: http://wwwsocialstyrelsense/Lists/ Artikelkatalog/Attachments/18394/2011-7-6pdf. Accessed April 3, 2019.

27. National Board of Health and Welfare. Kvalitet och innehåll i patientregistret. Utskrivningar från sluttenvården 1964-2007 och besök i specialiserad öppenvård (exclusive primärvårdsbesök) 19972007. Availabale from: http://wwwsocialstyrelsense/Lists/ Artikelkatalog/Attachments/8306/2009-125-15_200912515_rev2pdf. Accessed April 3, 2019. 
28. Statistics Sweden. Evaluering av utbildningsregistret 2006. Availabale from: http://wwwscbse/statistik/_publikationer/BE9999_ 2006A01_BR_BE96ST0604pdf. Accessed April 3, 2019.

29. Nager A, Sundquist K, Ramirez-Leon V, Johansson LM. Obstetric complications and postpartum psychosis: a follow-up study of 1.1 million first-time mothers between 1975 and 2003 in Sweden. Acta Psychiatr Scand. 2008;117(1):12-19.

30. Bergink V, Boyce P, Munk-Olsen T. Postpartum psychosis: a valuable misnomer. Aust N Z J Psychiatry. 2015;49(2):102-103. doi:10.1177/ 0004867414564698

31. Sharma V, Sommerdyk C. Postpartum psychosis: what is in a name? Aust N Z J Psychiatry. 2014;48(12):1081-1082. doi:10.1177/ 0004867414521502

32. Timmermans B. 2010. The Danish integrated database for labor market research: towards demystification for the English speaking audience. DRUID Working Papers Availabale from: http:// www3druiddk/wp/20100016pdf
33. Meltzer-Brody S, Larsen JT, Petersen L, et al. Adverse life events increase risk for postpartum psychiatric episodes: A population-based epidemiologic study. Depress Anxiety. 2018;35(2):160-167. doi:10.1002/da.22697

34. Bergink V, Laursen TM, Johannsen BM, Kushner SA, MeltzerBrody S, Munk-Olsen T. Pre-eclampsia and first-onset postpartum psychiatric episodes: a Danish population-based cohort study. Psychol Med. 2015;45(16):3481-3489. doi:10.1017/S00332 91715001269

35. Robertson E, Grace S, Wallington T, Stewart DE. Antenatal risk factors for postpartum depression: a synthesis of recent literature. Gen Hosp Psychiatry. 2004;26(4):289-295. doi:10.1016/j. genhosppsych.2004.04.005

36. Ludvigsson JF, Andersson E, Ekbom A, et al. External review and validation of the Swedish national inpatient register. BMC Public Health. 2011;11:450. doi:10.1186/1471-2458-11-450 


\section{Supplementary material}

Table SI International classification of diseases codes used to define causes of death and medical conditions

\begin{tabular}{|c|c|c|c|c|c|}
\hline \multirow{3}{*}{$\begin{array}{l}\text { Causes of death or medical } \\
\text { conditions }\end{array}$} & \multicolumn{5}{|l|}{ ICD $\operatorname{codes}^{a}$} \\
\hline & \multicolumn{2}{|l|}{ Denmark } & \multicolumn{3}{|l|}{ Sweden } \\
\hline & ICD-8 & ICD-IO & ICD-8 & ICD-9 & ICD-IO \\
\hline Unnatural death & $\begin{array}{l}\text { 795, E800- } \\
\text { E999 }\end{array}$ & R95-97, V00-Y99 & $\begin{array}{l}\text { 7959, 79,62I, } \\
\text { E807-E999 }\end{array}$ & $\begin{array}{l}\text { 798, E807- } \\
\text { E999 }\end{array}$ & $\begin{array}{l}\text { R95, R96, R98, V0I- } \\
\text { Y98 }\end{array}$ \\
\hline Any psychiatric disorder & $290-315$ & F00-F99 & $290-315$ & $290-319$ & F00-F99 \\
\hline $\begin{array}{l}\text { Psychotic or bipolar disorder before } \\
\text { the exposure period }\end{array}$ & $294.4,295-299$ & $\begin{array}{l}F 20-31, F 32.3, F 33.3 \\
F 53 . I\end{array}$ & $294.4,295-299$ & $295-299$ & $\begin{array}{l}\mathrm{F} 20-3 \mathrm{I}, \mathrm{F} 32.3, \mathrm{~F} 33.3 \\
\mathrm{~F} 53 . \mathrm{I}\end{array}$ \\
\hline Depression before the exposure period & 300.49 & $F 32, F 33, F 53.0$ & 300.4 & $300 E, 31 I$ & $F 32, F 33, F 53.0$ \\
\hline Anxiety before the exposure period & 300.09 & F4I & 300.0 & $300 \mathrm{~A}$ & F4I \\
\hline $\begin{array}{l}\text { Psychotic episode in the postpartum } \\
\text { period }\end{array}$ & $294.4,295-299$ & $\begin{array}{l}F 20-31, F 32.3, F 33.3 \\
F 53 . I\end{array}$ & $294.4,295-299$ & $295-298$ & $\begin{array}{l}\mathrm{F} 20-3 \mathrm{I}, \mathrm{F} 32.3, \mathrm{~F} 33.3 \\
\mathrm{~F} 53 . \mathrm{I}\end{array}$ \\
\hline $\begin{array}{l}\text { Psychotic episode or depression in the } \\
\text { postpartum period }\end{array}$ & $\begin{array}{l}294.4,295- \\
299,300.49\end{array}$ & $\begin{array}{l}F 20-31, F 32, F 33 \\
F 53.0, F 53 . I, F 39\end{array}$ & $\begin{array}{l}294.4,295-299, \\
300.4\end{array}$ & $\begin{array}{l}295-298 \\
300 E, 31 I\end{array}$ & $\begin{array}{l}F 20-31, F 32, F 33, \\
F 53.0, F 53 . I, F 39\end{array}$ \\
\hline
\end{tabular}

Notes: aln Denmark ICD-8 was used during 1967-1993 and ICD-I0 since 1994, while in Sweden ICD-8 was used during 1968-1986, ICD-9 during I987-I996 and ICD-I0 since 1997. Abbreviations: ICD, International Classification of Diseases.

Table S2 Unadjusted hazard ratios for a psychotic episode in the 90 days postpartum by covariates

\begin{tabular}{|c|c|c|c|c|}
\hline \multirow[t]{2}{*}{ Variable } & \multicolumn{2}{|c|}{$\begin{array}{l}\text { Births by women with no history of } \\
\text { psychiatric disorder before delivery }\end{array}$} & \multicolumn{2}{|c|}{$\begin{array}{l}\text { Births by women with a history of psy- } \\
\text { chiatric disorder at the start of the } \\
\text { exposure period }^{\text {b }}\end{array}$} \\
\hline & Events/N & HR (95\% CI) & Events/N & HR $(95 \% \mathrm{CI})$ \\
\hline $\begin{array}{l}\text { Country } \\
\text { Sweden } \\
\text { Denmark }\end{array}$ & $\begin{array}{l}1109 / 2829958 \\
379 / 1344353\end{array}$ & $\begin{array}{l}1.00 \\
0.72(0.64-0.81)\end{array}$ & $\begin{array}{l}1134 / 70908 \\
437 / 45415\end{array}$ & $\begin{array}{l}1.00 \\
0.60(0.53-0.68)\end{array}$ \\
\hline $\begin{array}{l}\text { Woman's country of origin } \\
\text { Denmark/Sweden } \\
\text { Other country }\end{array}$ & $\begin{array}{l}1435 / 4046744 \\
51 / / 25520\end{array}$ & $\begin{array}{l}1.00 \\
1.15(0.86-1.52)\end{array}$ & $\begin{array}{l}1515 / 111988 \\
55 / 4310\end{array}$ & $\begin{array}{l}1.00 \\
0.95(0.7|-| .26)\end{array}$ \\
\hline $\begin{array}{l}\text { Woman's age at delivery (in years) } \\
\begin{array}{l}19 \text { or less } \\
20-24 \\
25-29 \\
30-34 \\
35 \text { or more }\end{array}\end{array}$ & 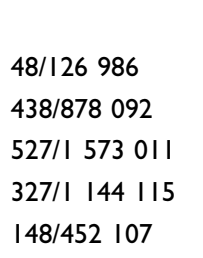 & $\begin{array}{l}\text { I.I3 (0.84-I.52) } \\
\text { I.49 (I.3I-I.69) } \\
1.00 \\
0.85(0.74-0.98) \\
0.98(0.81-1.18)\end{array}$ & $\begin{array}{l}9 / 4574 \\
184 / 25027 \\
518 / 37967 \\
536 / 30973 \\
324 / 17782\end{array}$ & $\begin{array}{l}0.14(0.07-0.28) \\
0.54(0.45-0.64) \\
1.00 \\
1.27(1.12-1.44) \\
1.34(1.16-1.55)\end{array}$ \\
\hline $\begin{array}{c}\text { Year of delivery } \\
1973-1982 \\
1983-1992 \\
1993-2002 \\
2003-2008\end{array}$ & $\begin{array}{l}515 / 892974 \\
558 / 1335521 \\
309 / 1319037 \\
106 / 626779\end{array}$ & $\begin{array}{l}3.41(2.75-4.23) \\
2.47(2.00-3.06) \\
1.39(1.11-1.74) \\
1.00\end{array}$ & $\begin{array}{l}261 / 9899 \\
661 / 30526 \\
448 / 42489 \\
201 / 33409\end{array}$ & $\begin{array}{l}4.42(3.65-5.36) \\
3.63(3.07-4.28) \\
1.76(1.48-2.09) \\
1.00\end{array}$ \\
\hline $\begin{array}{l}\text { Parity } \\
\text { Primiparous } \\
\text { Multiparous }\end{array}$ & $\begin{array}{l}953 / 1861874 \\
535 / 2312436\end{array}$ & $\begin{array}{l}2.21(1.99-2.46) \\
1.00\end{array}$ & $\begin{array}{l}808 / 48311 \\
763 / 68012\end{array}$ & $\begin{array}{l}1.50(1.36-1.65) \\
1.00\end{array}$ \\
\hline
\end{tabular}

(Continued) 
Table S2 (Continued).

\begin{tabular}{|c|c|c|c|c|}
\hline \multirow[t]{2}{*}{ Variable } & \multicolumn{2}{|c|}{$\begin{array}{l}\text { Births by women with no history of } \\
\text { psychiatric disorder before delivery }\end{array}$} & \multicolumn{2}{|c|}{$\begin{array}{l}\text { Births by women with a history of psy- } \\
\text { chiatric disorder at the start of the } \\
\text { exposure period }^{\text {b }}\end{array}$} \\
\hline & Events/N & HR (95\% CI) & Events/N & HR (95\% CI) \\
\hline $\begin{array}{l}\text { Woman's education } \\
\text { Basic school } \\
\text { Secondary school } \\
\text { College/university }\end{array}$ & $\begin{array}{l}290 / 667014 \\
687 / 1897544 \\
469 / 1551056\end{array}$ & $\begin{array}{l}1.44(1.24-1.67) \\
1.20(1.06-1.35) \\
1.00\end{array}$ & $\begin{array}{l}424 / 33612 \\
677 / 49706 \\
439 / 31492\end{array}$ & $\begin{array}{l}0.90(0.78-1.05) \\
0.98(0.86-1.12) \\
1.00\end{array}$ \\
\hline $\begin{array}{l}\text { Smoking in early pregnancy } \\
\text { No } \\
\text { Yes }\end{array}$ & $\begin{array}{l}633 / 2233080 \\
188 / 563419\end{array}$ & $\begin{array}{l}1.00 \\
1.18(1.00-1.39)\end{array}$ & $\begin{array}{l}565 / 55965 \\
495 / 35753\end{array}$ & $\begin{array}{l}1.00 \\
1.37(1.21-1.56)\end{array}$ \\
\hline $\begin{array}{l}\text { Obesity } \\
\text { No } \\
\text { Yes }\end{array}$ & $\begin{array}{l}226 / 928416 \\
22 / 92280\end{array}$ & $\begin{array}{l}1.00 \\
0.98(0.62-1.55)\end{array}$ & $\begin{array}{l}299 / 3 \mid 149 \\
56 / 4093\end{array}$ & $\begin{array}{l}1.00 \\
1.43(1.06-1.93)\end{array}$ \\
\hline $\begin{array}{l}\text { Partner's psychiatric disorder up to } \\
\text { one year before conception } \\
\text { No } \\
\text { Yes }\end{array}$ & $\begin{array}{l}|45| / 4077359 \\
37 / 96952\end{array}$ & $\begin{array}{l}1.00 \\
1.08(0.78-1.49)\end{array}$ & $\begin{array}{l}1288 / 105288 \\
283 /|| 035\end{array}$ & $\begin{array}{l}1.00 \\
2.11(1.84-2.42)\end{array}$ \\
\hline $\begin{array}{l}\text { Psychiatric disorder in parents or } \\
\text { siblings of the woman up to one year } \\
\text { before conception } \\
\text { No } \\
\text { Yes }\end{array}$ & $\begin{array}{l}\mid 231 / 3636 \quad 39 \\
257 / 538 \quad 172\end{array}$ & $\begin{array}{l}1.00 \\
1.41(1.23-1.62)\end{array}$ & $\begin{array}{l}1101 / 79716 \\
470 / 36607\end{array}$ & $\begin{array}{l}1.00 \\
0.93(0.83-1.04)\end{array}$ \\
\hline
\end{tabular}

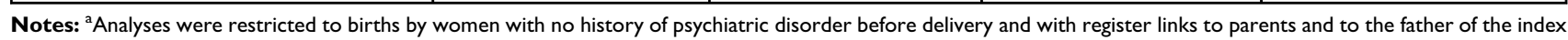
child $(\mathrm{n}=4 \mathrm{I} 74 \mathrm{3} \mathrm{II})$. ${ }^{\mathrm{b}}$ Analyses were restricted to births by women with a history of a psychiatric disorder at the start of the exposure period and with register links to parents and the father of the index child $(n=116323)$. 'Available in Sweden since 1990.

Abbreviations: $\mathrm{N}$, number; $\mathrm{HR}$, hazard ratio; $\mathrm{Cl}$, confidence intervals. 
Table S3 Hazard ratios for a recurrent psychotic episode in the 90 days postpartum according to death of a close relative the year before or during pregnancy among women with a history of a psychotic or bipolar disorder before the start of the exposure period

\begin{tabular}{|c|c|c|c|}
\hline Exposure & $\mathbf{N}$ & Events & Adjusted HR (95\% CI) \\
\hline \multicolumn{4}{|c|}{ Any loss of a close relative the year before or during pregnancy ${ }^{a}$} \\
\hline Unexposed & 12950 & 1289 & 1.00 \\
\hline Any loss & 591 & 57 & $1.01(0.77-1.33)$ \\
\hline \multicolumn{4}{|l|}{ Time of the relative's death ${ }^{\mathrm{a}}$} \\
\hline The year before pregnancy & 355 & 32 & $0.94(0.66-1.34)$ \\
\hline During pregnancy & 236 & 25 & $1.12(0.75-1.67)$ \\
\hline \multicolumn{4}{|l|}{ Cause of the relative's death ${ }^{\mathrm{a}}$} \\
\hline Death due to natural cause & 505 & 48 & $1.00(0.74-1.35)$ \\
\hline Death due to unnatural cause & 83 & 9 & $1.12(0.58-2.14)$ \\
\hline \multicolumn{4}{|l|}{ Type of lost relative } \\
\hline Death of a parent or sibling ${ }^{\mathrm{b}}$ & 554 & 51 & $0.90(0.68-1.19)$ \\
\hline Death of the partner or older child ${ }^{c}$ & 66 & 9 & $1.70(0.91-3.20)$ \\
\hline
\end{tabular}

Notes: a Analyses were restricted to births by women who had register links to parents and to the father of the index child ( $n=1354 I)$. Adjustment was made for country, year of delivery, woman's age at the child's birth, country of origin, highest attained education, parity and psychiatric disorder in her parents, siblings and partner before the exposure period. ${ }^{b}$ Analyses were restricted to births by women who had register links to parents and at least a live parent or a live sibling at the start of the exposure period $(n=14$ 0 I7). Adjustment was made for country, year of delivery, woman's age at the child's birth, country of origin, highest attained education, parity and psychiatric disorder before the exposure period in her parents and siblings. 'Analyses were restricted to births by women with register links to the father of the index child ( $\mathrm{n}=15 \mathrm{5} / 7$ ). Adjustment was made for country, year of delivery, woman's age at the child's birth, country of origin, highest attained education, parity and her partner's psychiatric disorder before the exposure period.

Abbreviations: $\mathrm{N}$, number; $\mathrm{HR}$, hazard ratio; $\mathrm{Cl}$, confidence interval.

Table S4 Hazard ratios for a psychotic episode in the 90 days postpartum according to death of a close relative the year before or during pregnancy among women with a history of a depression or anxiety before the start of the exposure period

\begin{tabular}{|l|l|l|l|}
\hline Exposure $^{\mathbf{a}}$ & $\mathbf{N}$ & Events & Adjusted HR (95\% CI) \\
\hline $\begin{array}{l}\text { Any loss of a close relative the year before or during pregnancy } \\
\text { Unexposed } \\
\text { Any loss }\end{array}$ & $\begin{array}{l}27116 \\
1053\end{array}$ & $\begin{array}{l}266 \\
12\end{array}$ & $\begin{array}{l}1.00 \\
1.05(0.59-1.87)\end{array}$ \\
\hline $\begin{array}{l}\text { Time of the relative's death } \\
\text { The year before pregnancy }\end{array}$ & 613 & 6 & $0.92(0.41-2.05)$ \\
During pregnancy & 440 & 6 & $1.23(0.54-2.77)$ \\
\hline
\end{tabular}

Notes: ${ }^{2}$ Analyses by the cause of the relative's death and the type of deceased relative are not presented since the number of events was below the number/cell that we may report according to Danish law. ${ }^{b}$ Analyses were restricted to births by women who had register links to parents and to the father of the index child ( $\mathrm{n}=28 \mathrm{I} 69$ ). Adjustment was made for country, year of delivery, the woman's age at the child's birth, country of origin, highest attained education, parity and psychiatric disorder in her parents, siblings and partner before the exposure period.

Abbreviations: $\mathrm{N}$, number; $\mathrm{HR}$, hazard ratio; $\mathrm{Cl}$, confidence interval. 
Table S5 Hazard ratios for a psychotic episode or depression in the 90 days postpartum according to death of a close relative the year before or during pregnancy

\begin{tabular}{|c|c|c|c|c|}
\hline \multirow[t]{2}{*}{ Exposure } & \multicolumn{2}{|c|}{$\begin{array}{l}\text { Births by women with no his- } \\
\text { tory of psychiatric disorder } \\
\text { before delivery }\end{array}$} & \multicolumn{2}{|c|}{$\begin{array}{l}\text { Births by women with a his- } \\
\text { tory of psychiatric disorder at } \\
\text { the start of the exposure } \\
\text { period }\end{array}$} \\
\hline & Events & $\begin{array}{l}\text { Adjusted HR (95\% } \\
\text { CI) }\end{array}$ & Events & $\begin{array}{l}\text { Adjusted HR (95\% } \\
\text { CI) }\end{array}$ \\
\hline \multicolumn{5}{|c|}{$\begin{array}{l}\text { Any loss of a close relative the year before or during } \\
\text { pregnancy }\end{array}$} \\
\hline Unexposed & 2747 & 1.00 & 2079 & 1.00 \\
\hline Any loss & 98 & $1.12(0.91-1.37)$ & 77 & $0.91(0.72-1.15)$ \\
\hline \multicolumn{5}{|l|}{ Time of the relative's death ${ }^{\mathrm{a}}$} \\
\hline The year before pregnancy & 60 & $1.16(0.89-1.50)$ & 41 & $0.83(0.6 \mathrm{I}-\mathrm{I} .14)$ \\
\hline During pregnancy & 38 & $1.07(0.77-1.47)$ & 36 & $1.02(0.73-1.43)$ \\
\hline \multicolumn{5}{|l|}{ Cause of the relative's death ${ }^{\mathrm{a}}$} \\
\hline Death due to natural cause & 87 & $1.14(0.92-1.4 I)$ & 64 & $0.88(0.68-1.14)$ \\
\hline Death due to unnatural cause & II & $1.03(0.55-1.91)$ & 12 & $1.05(0.60-1.85)$ \\
\hline \multicolumn{5}{|l|}{ Type of lost relative } \\
\hline Death of a parent or sibling ${ }^{\mathrm{b}}$ & 93 & $1.13(0.91-1.39)$ & 70 & $0.85(0.67-1.09)$ \\
\hline Death of the partner or older child ${ }^{c}$ & 11 & $1.03(0.53-1.98)$ & 11 & $1.21(0.67-2.20)$ \\
\hline
\end{tabular}

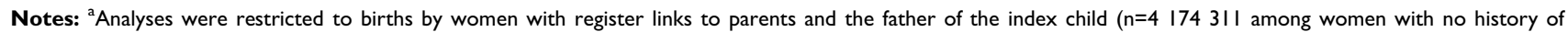
psychiatric disorder before delivery and $n=116323$ among women with a history of psychiatric disorder at the start of the exposure period). Adjustment was made for country, year of delivery, the woman's age at the child's birth, country of origin, highest attained education, parity and psychiatric disorder in her parents, siblings and partner before the exposure period. ${ }^{b}$ Analyses were restricted to births by women who had register links to parents and at least a live parent or sibling at the start of the exposure period ( $n=4217690$ among women with no history of psychiatric disorder before delivery and n=119 769 among women with a history of psychiatric disorder at the start of the exposure period). Adjustment was made for country, year of delivery, the woman's age at the child's birth, country of origin, highest attained education, parity and psychiatric disorder before the exposure period in the her parents and siblings. 'Analyses were restricted to births by women with register links to the father of the index child ( $\mathrm{n}=5040 \mathrm{I} 6 \mathrm{I}$ among women with no history of psychiatric disorder before delivery and $\mathrm{n}=130 \mathrm{I} 88$ among women with a history of psychiatric disorder at the start of the exposure period). Adjustment was made for country, year of delivery, the woman's age at the child's birth, country of origin, highest attained education, parity and her partner's psychiatric disorder before the exposure period.

Abbreviations: $\mathrm{N}$, number; $\mathrm{HR}$, hazard ratio; $\mathrm{Cl}$, confidence interval.

\section{Publish your work in this journal}

Clinical Epidemiology is an international, peer-reviewed, open access, online journal focusing on disease and drug epidemiology, identification of risk factors and screening procedures to develop optimal preventative initiatives and programs. Specific topics include: diagnosis, prognosis, treatment, screening, prevention, risk factor modification, systematic reviews, risk \& safety of medical interventions, epidemiology \& biostatistical methods, and evaluation of guidelines, translational medicine, health policies \& economic evaluations. The manuscript management system is completely online and includes a very quick and fair peer-review system, which is all easy to use. 